\title{
FMEA ANALYSIS OF XEIKON ELECTROPHOTOGRAPHICS
}

\author{
Plehati, S.; PAVlovic, T.; Bogovic, T.; \\ PAP, K. \& ZILJAK VUJIC, J.
}

Abstract: By introducing FMEA analysis of Xeikon DCP32D electrophotographic printing model it is shown which components of the machine are weakest link in the printing. Each component is shown separately according to the modules and units of the machine, so that the critical component of each module can be read. By observing the critical component we can improve printing results and minimize cost of production. Solution is in improving critical component and suggestion is to evaluate and validate this component using FMEA analysis.

Key words: Xeikon FMEA, Xeikon electrophotographic model, failures in digital printing, corona wire failure, scorotron failure
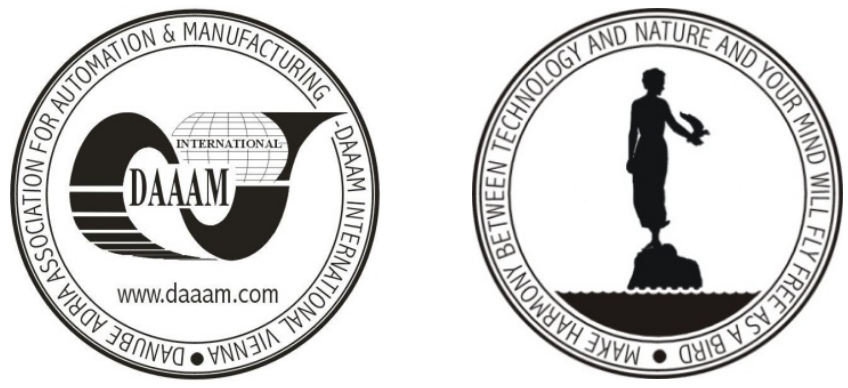

Authors' data: B.Eng. Plehati, S[ilvio]**; B.Eng. Pavlovic, T[omislav]**; B.Eng. Bogovic, T[omislav]**; Dr. Sc. Pap, K[laudio]*; Dr. Sc. Ziljak Vujic, J[ana]**, *University of Graphic Arts, Getaldiceva 2, 10000, Zagreb, Croatia, ** Polytechnic of Zagreb, Vrbik 8, 10000, Zagreb, Croatia, splehati@gmail.com, tpavlovic@gmail.com,_bogovic.t@gmail.com,_klaudio.pap@zg.t-com.hr, janazv@tvz.hr

This Publication has to be referred as: Plehati, S[ilvio]; Pavlovic, T[omislav]; Bogovic, T[omislav]; Pap, K[laudio] \& Ziljak Vujic, J[ana] (2009). FMEA Analysis of Xeikon Electrophotographics, Chapter 95 in DAAAM International Scientific Book 2009, pp. 977-984, B. Katalinic (Ed.), Published by DAAAM International, ISBN 978-3-901509-69-8, ISSN 1726-9687, Vienna, Austria

DOI: 10.2507/daaam.scibook.2009.95 